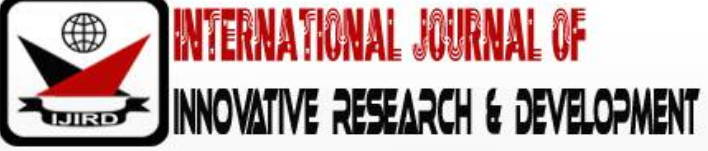

ISSN 2278-0211 (Online)

\section{Optimization Technique for Hydrokinetic Turbine Blades: Pressure Minimization Approach}

\author{
Akinnibosun Abiola Micheal \\ Researcher, Department of Mechanical Engineering, \\ University of Ibadan, Nigeria
}

\begin{abstract}
:
Everyday rise in world population push for more energy demand. The dependence and usage of fossil fuel in an uncontrolled manner has triggered environmental imbalance. A need to discourage the use of fossil fuel birth renewable energy is a form of energy which is not just environmentally friend but relatively cheap. Hydrokinetic turbine is a device which extracts kinetic energy from moving water to generate power. Hydrokinetic blade is an integral part of hydrokinetic turbine which is one of the components that determines the output power. There is power loss during the operation of the turbine and there is need to reduce this loss. This gives rise to a need to develop an optimization technique that can optimize turbine blade in addition to the existing models. Parameters concentrated on include pressure coefficient, axial induction factor, tangential induction factor, local tip speed ratio and angle of flow
\end{abstract}

Keywords: Hydrokinetic turbine blade, mathematical model, optimization, MatLab

\section{Introduction}

The ever increase in human population across the globe has caused the demand for fossil energy to skyrocket (Akinnibosun et.al,2015); this has subsequently caused a switch towards renewable source of energy to compensate and cater for the environmental imbalance caused by the usage of fossil fuel such as excessive depletion of the ozone layer. Several renewable energies such as hydro power, wind power etc. are used to compliment energy demand which fossil fuel cannot cater for (Nitin etal., 2013). In the cause of the usage of hydrokinetic turbine blades to extract power from moving water; there are several losses due to design, specification and operating principles. There is need to maximize the performance of hydrokinetic turbine blade under various operating conditions. Thus, this work aims to optimize horizontal axis turbine blade using gradient method of optimization.

The shape of the blades of hydrokinetic turbine plays a significant role in determining the overall hydrodynamic performance of horizontal axis hydrokinetic turbine. Thus, hydrodynamic optimization of the shape of blade is very essential in the design and manufacturing of hydrokinetic turbines (Eke and Onyewudiala, 2010). Before the recent times, the Wilson and Glauert methods were usually used for blade design (Spera, 1994). The goal of blade design is to augment the ratio of lift to drag ratio by increasing lift and reducing drag (Genc, 2009).The broad objectives of these methods were to obtain the maximum coefficient of performance of the blade at the design water velocity. Furthermore, the design results from the above said methods must be substantially corrected to get smooth chord length and twist distributions (Spera, 1994). Several optimization techniques have been used in the time for optimizing turbine. Genetic Algorithm is one of the methods that has been used to optimize wind turbine (Eke and Onyewudiala, 2010). Another technique of optimization being used for the optimization of blade is Meta Heuristic method (Anjali et al, 2014). Glauert's optimal rotor theory of horizontal axis wind turbine was designed (Nitin et al, 2010). The usual search algorithms been used such as the feasible direction method and complex method are faced with challenge of converging on the local optimal point (Genc, 2009).

In solving complex problems; obtaining a global optimal result is often the challenge (Eke and Onyewudiala, 2010). This is because getting a global optimized point is a function of user interference and algorithmic skills. Cavitation is one of criteria which limit the performance of hydrokinetic turbine. Although in the selection of hydrofoil, the ratio of coefficient of lift to coefficient of drag should be as high as possible but cavitation number should be kept as low as possible (Crimi,2012).However, the lift coefficient and the drag coefficient are also influenced by parameters such as angle of attack (Ahmed, 2012). Out of the blade sections; the region being affected most is the blade tip which mostly cut the fluid. Several institutions have done theoretical and experimental studies in developing hydrofoils. Out of the several hydrofoil developers; some of the most common are RIS $\boldsymbol{\phi}$, Eppler, Gottingen, U.S. National Aeronautics and Space Administration (NASA), National Renewable Energy Laboratory (NREL) (Muratoglu and Yuce,2015).

In this study, an efficient mathematical model is developed to optimize hydrofoils of horizontal axis hydrokinetic turbine in which the optimal values of turbine parameters are determined using a gradient optimization approach. The implementation of the model is achieved by the aid of MATLAB code. 


\section{Basic Hydrofoil Terminologies}

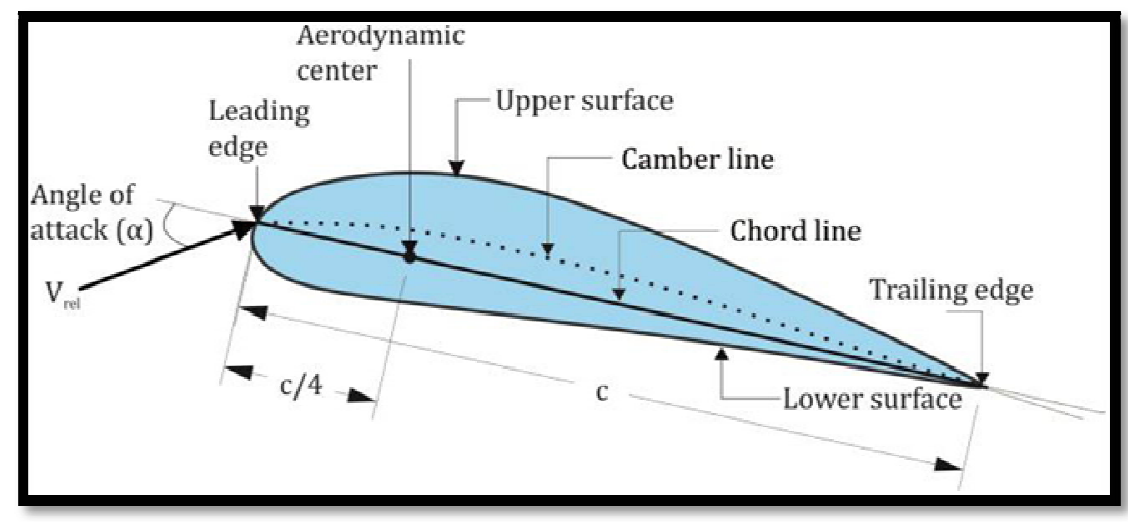

Figure 1: A Diagram of Hydrofoil Revealing Its Essential Part

The figure above shows the essential part of hydrofoil. The rear edge of the portion of hydrofoil where the fluid separated by the forward region rejoins is called the trailing edge. Hydrofoil surface usually have an upper surface and lower surface; the forward region where the upper surface and lower surface intersects is the leading edge. Chord line is that straight line which joins the forward region and the rear region of the hydrofoil. The thickness of the hydrofoil is the length between the lower surface and upper surface at right angle to the line linking the leading edge to the trailing edge. Maximum camber is the highest possible vertical distance between camber line and chord line. Camber line is the arc connecting the leading edge to the trailing edge. Hydrodynamic center is the point along the chord length (close to the leading edge) where the chord line is one-fourth from the leading edge. Upper surface of the hydrofoil is the higher portion of the hydrofoil surface while the lower surface is the down surface part of the hydrofoil. The angle of attack is the angle between the relative fluid velocity and chord line.

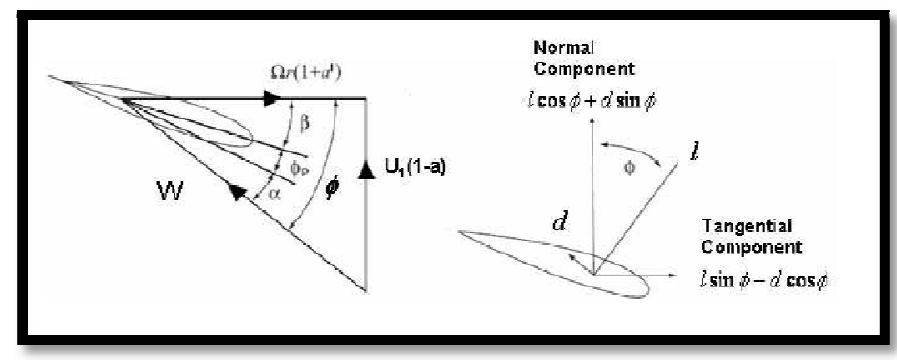

Figure 2: Forces Acting on Hydrofoil

\subsection{Angle of Flow}

This is the angle between the rotor plane and relative fluid velocity. Section pitch angle is between rotor plane and chord line. Reference pitch angle is the pitch angle at the tip of the blade.

\section{Methodology}

\subsection{Forces of Fluid Dynamics}

Various forces due to pressure, fluid friction and velocity changes act on horizontal axis hydrokinetic turbine blade submerged in a stream flow. These forces include drag and lift. The drag force is as a result of pressure variation at the hydrofoil surface and viscosity (Manwell et al, 2009). Whenever fluid moves over hydrofoil; the fluid particles at the upper region of the hydrofoil surface possess a greater velocity and low pressure while the velocity of the fluid particles at the lower region of the hydrofoil surface possess a low velocity with a compensated high pressure. These variations in pressure birth lift force. Many factors determine the ratio in which the lift and drag force exist. This includes angle of attack, section pitch angle, angle of flow, hydrofoil geometry etc. Drag and lift force can be expressed as;

$F_{D}=0.5 C_{D} j c \rho U^{2}$

$F_{L}=0.5 C_{L} j c \rho U^{2}$

Where $F_{D}, F_{L}, C_{D}, C_{L}, j, c, U$ are drag force, lift force, coefficient of drag, coefficient of lift, span length, chord length and velocity respectively.

\subsubsection{Cavitation}

Cavitation effect on hydrokinetic turbine is majorly a function of pressure coefficient which is ratio of pressure difference to stagnation pressure. The coefficient of pressure can be expressed as; $J=\frac{P_{2}-P_{1}}{\frac{1}{2} \rho U_{1}^{2}}$ 


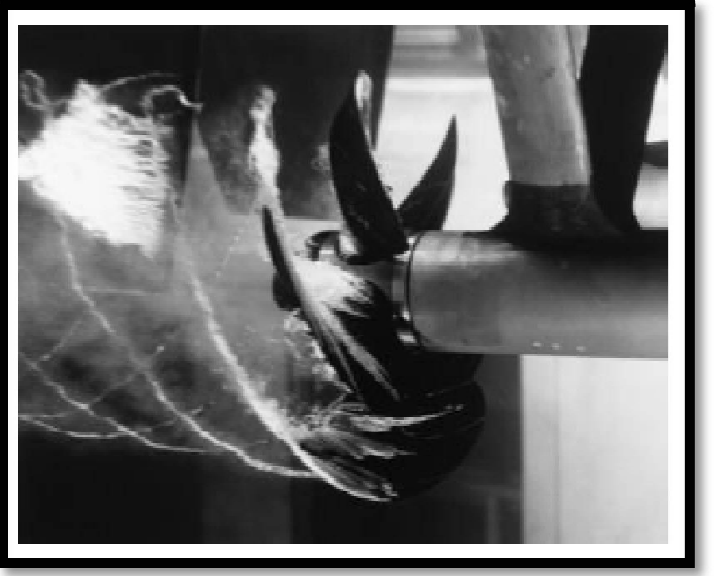

Figure 3: Cavitation at the Propeller Blade Tips in a Water Tunnel Test

As presented by (Person, 2009; Grasso, 2012), the following equations can be used to determine the existence and evaluate cavitation number $\boldsymbol{\delta}$ present.

$\boldsymbol{\delta}=\frac{P_{0}-P_{v}}{m}$

$U_{\text {rel }}=\sqrt{\left[U_{\infty}^{2}\left(1-a^{2}\right)+(\Omega r)^{2}(1+b)^{2}\right]}$

The blade is said to experience cavitation if velocity of cavitation $\left(U_{\text {cavitate }}\right)$ exceeds relative velocity (Person, 2009).

$$
U_{\text {cavitate }}=\sqrt{\frac{P_{a t m}+\rho g h+0.5 \rho U_{\infty}{ }^{2} a(2-a)-0.5 \rho(\Omega r b)^{2}-P_{v}}{-0.5 \rho J_{\text {min }}}}
$$

Where $P_{0}$ is the local pressure, $P_{v}$ is the vapor pressure, $\mathrm{m}$ is the dynamic pressure.

\subsubsection{Mathematical Model}

A mathematical model which can optimize turbine blade was developed while concentrating more on the blade region neglecting the event at upstream and downstream. The region under consideration was subdivided into three; the inlet region just before the blade, the hydrofoil region and the outlet region immediately after the blade. The mathematical model was formed with the maximizing power coefficient by keeping the outlet pressure as minimum as possible but above a specific value which cavitation can be avoided.

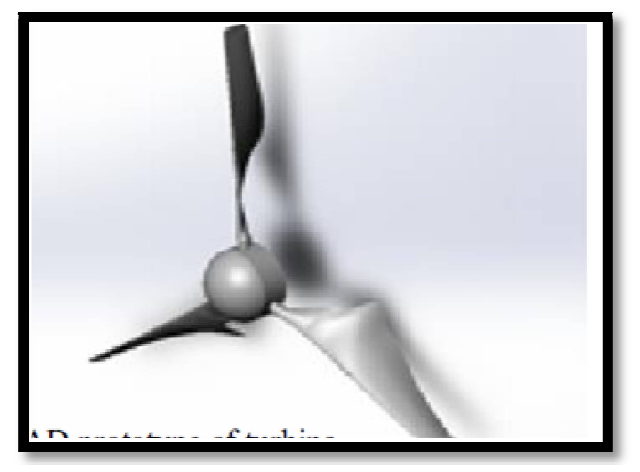

Figure 4: CAD Prototype of Turbine Blade

From fluid mechanics analysis; the pressure coefficient which is a dimensionless number can be express as a ratio of pressure difference to stagnation pressure. The pressure difference can be expressed as;

$\left.P_{2}-P_{1}=\frac{1}{2} \rho U_{1}^{2}\left[1-a^{2}+2 \lambda_{r}(a-1)\left(1+a^{\prime}\right) \tan \phi\right)\right]$

For more explicitly analysis; pressure coefficient can be expressed as;

$\left.J=\left[1-a^{2}+2 \lambda_{r}(a-1)\left(1+a^{\prime}\right) \tan \phi\right)\right]$

From equation above; pressure coefficient can be expressed as a function of axial induction factor, tangential induction factor, local tip speed ratio and angle of flow

$\left.J=\left[1-\left\{\frac{1}{\frac{4 F \sin ^{2}(\alpha+\beta)}{\sigma C_{a}}+1}\right\}^{2}+2 \lambda_{r}\left(\frac{1}{\frac{4 F \sin ^{2}(\alpha+\beta)}{\sigma C_{a}}+1}\right\}-1\right)\left(1+\frac{1}{\frac{2 F \sin 2(\alpha+\beta)}{\sigma C_{r}}-1}\right) \tan (\alpha+\beta)\right]$ 
In the equation above; the pressure coefficient is expressed as a function of angle of attack, section pitch angle, solidity, coefficient of torque, coefficient of thrust, tip loss factor.

\subsubsection{Optimization Techniques}

The aim of any optimization technique is to minimize/maximize objective function depending on the nature of the objective function. There are several means of optimization techniques. The one adopted in this study is gradient method of optimization.

The gradient optimization technique is a technique which takes the advantage of the derivative of dependent variable with respect to independent variable(s). In gradient method of optimization; the following sub-methods can be used. This includes steepest descent method, conjugate gradient method, Newton's method, modified Newton's method, etc. (Onwubiko, 2000; Hakanen, 2014). In this work, the adopted mode of gradient optimization technique being used is the conjugate gradient method of optimization. The conjugate method of gradient optimization is being used because it is a small modification to the steepest descent method which takes into account the history of the gradients to move more directly towards the optimum. If there is need to do ' $q$ ' iterations with a starting point $y_{q}$. The general algorithm for gradient optimization technique is stated below:

- Test for convergence: If the conditions for convergence are satisfied, then stop and thus $y_{q}$ is the solution

- Compute a search direction: Compute the non-zero vector $c_{q}$ which defines the direction in n-space.

- Compute the step length: Find a positive scalar, such that $\xi_{q} \mathrm{f}\left(y_{q}+\xi_{q} c_{q}\right)<\mathrm{f}\left(y_{q}\right)$

- Update the estimate for minimum: Set $y_{q+1}=y_{q}+\xi_{q} c_{q}$. If $q=q+1$; go back to 1 (Belegundu and Chandrupatla, 1999).

The programming language used for this research work is MATLAB. MATLAB code was written to in tune to gradient optimization technique method to implement and solve the derivative equations. This is done to achieve the optimal conditions/points/values of the variables in the newly-developed mathematical model. MATLAB was chosen because of its flexibility, lesser time of debugging as compared to FOTRAN, versatility, matrix format of operation which make it easier to solve multiple simultaneous equations.

\section{Result and Inference}

The mathematical model formed was implemented using a MatLab code and graphs were generated when outlet pressure was plotted against each of the independent variables; axial induction factor, tangential induction factor, local tip speed ratio and angle of flow.

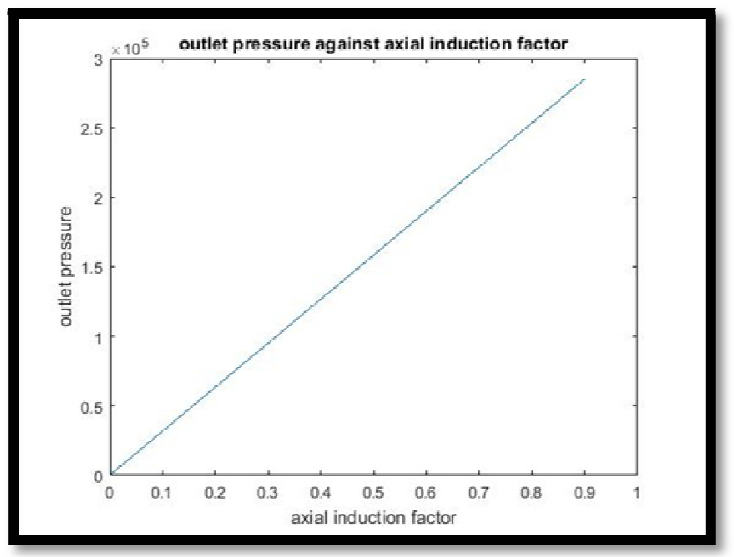

Figure 5: Graph of Outlet Pressure against Axial Induction Factor

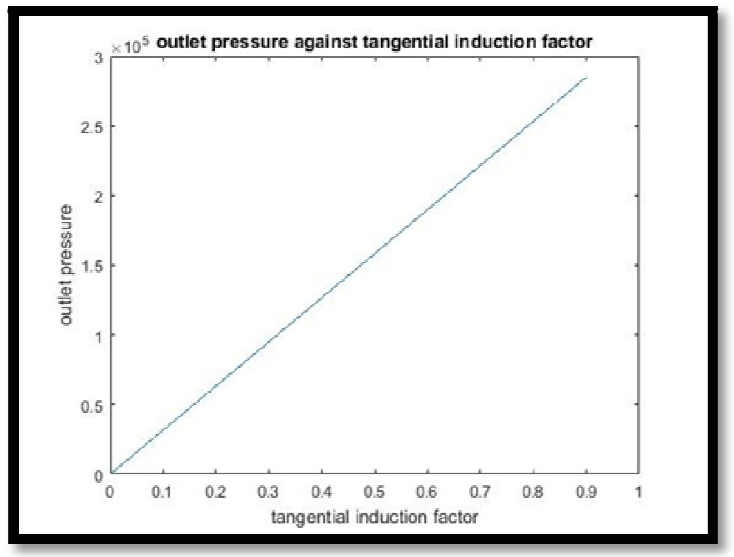

Figure 6: Graph of Outlet Pressure against Tangential Induction Factor 


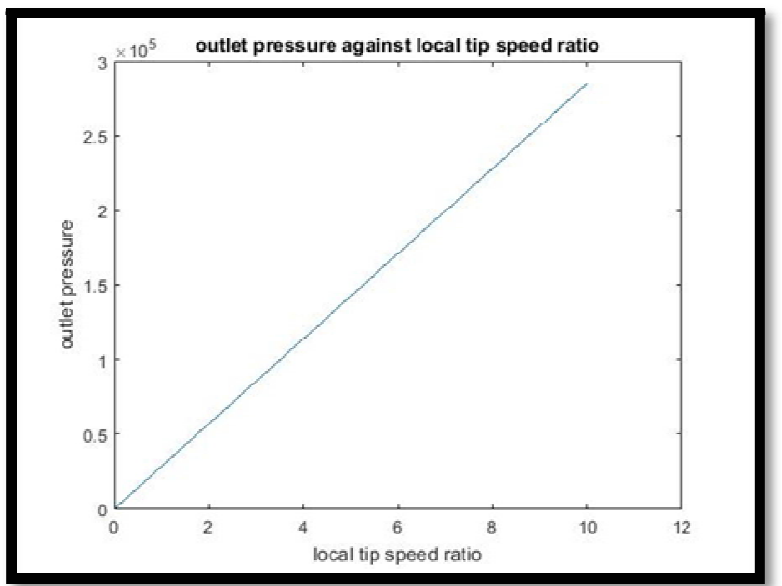

Figure 7: Graph of Outlet Pressure against Local Tip Speed Ratio

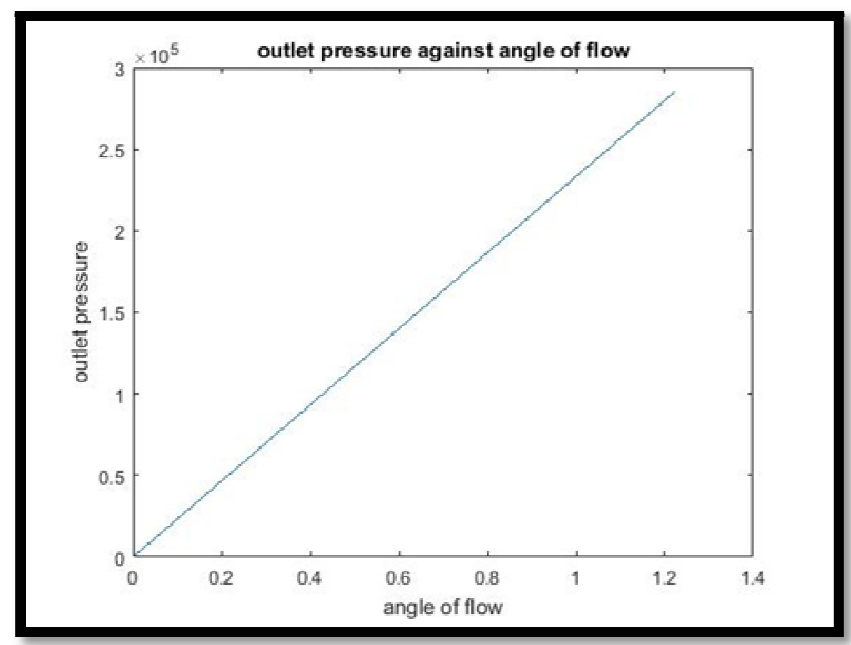

Figure 8: Graph of Outlet Pressure against Angle of Flow

From the above figures; the outlet pressure is seen to be approximately directly proportional to axial induction factor, tangential induction factor, local tip speed ratio and angle of flow. Hence, the axial induction factor, tangential induction factor, local tip speed ratio and angle of flow are directly related to one another. Axial induction factor is the ratio of difference between the inlet fluid velocity and velocity of the blade to the inlet fluid velocity. The more the extracted energy by the hydrokinetic turbine blade the lower the difference between the inlet fluid velocity and the velocity of the blade thus this causes a small axial induction factor which gives rise to a low outlet pressure. Although; the axial induction factor cannot be practically zero thus a zero-outlet pressure shown on the origin of the graph is not achievable. The smaller the outlet pressure; the higher the power extracted from the turbine. Thus, a low axial induction factor causes a low pressure and greater power extracted by the turbine blade. The maximum power coefficient can be achieved at the least achievable axial induction factor. The greatest challenge to keeping the outlet pressure as low as possible is cavitation. But cavitation velocity can be calculated as presented by (Person, 2009) such that cavitation occurs if and only if cavitation velocity exceeds the relative velocity of the fluid thus cavitation velocity is meant to be less than relative velocity if cavitation is to be avoided.

\section{Conclusion}

Apart from improving on the structural properties and design of horizontal axis hydrokinetic blade and its model; minimizing the outlet pressure by taking proper control of parameters such as axial induction factor, tangential induction factor, local tip speed ratio and angle of flow can improve the performance of blades and as well improve the overall turbine performance.

\section{References}

i. $\quad$ D Belegundu. and T. R. Chandrupatla Optimization Concepts and Applications, 1999.

ii. A.M Akinnibosun., Y.O Idowu., A.A Adeleke., W.O Ige, Comparative Briquetting of Coconut Shell and Husk. An Unpublished Undergraduate Project Work, Department of Mechanical Engineering, Ladoke Akintola University of Technology, Ogbomoso, 2015

iii. Onwubiko. Introduction to Engineering Design Optimization, chapter 4. Prentice Hall,2000

iv. D.A.Spera, Wind turbine technology: Fundamental Concepts of Wind Turbine Engineering. ASME Press, New York.Engineering, chapter 3. Prentice Hall 1994

v. F. Grasso, 'Design and optimization of tidal turbine airfoil,' Journal of Aircraft, vol. 49, no. 2, pp. 636-643, 2012. 
vi. G.B. Eke, J.I.Onyewudiyala (2010), Optimization of Wind turbine blades using Genetic Algorithm , Global Journal of Researches in Engineering, Volume 10. Issue 7 pp 22-26.

vii. J. Hakanen, Introduction to unconstrained optimization (gradient based method), 2014.

viii. J. Nocedal and S. J. Wright. Numerical Optimization. Springer, 2nd edition, 2006.

ix. M. Anjali, C. T.Sasanka, Ch.Deva Rajand, RavindraK. Meta Heuristic Method for the Design Optimization of a Wind Turbine Blade.2014

x. M. R. Ahmed,'Blade sections for different turbine and tidal current turbine applications-current status and future challenges,'International Journal of Energy Research, vol. 36, no. 7, pp. 829-844, 2012.

xi. M. S. Genç, 'Kanat profilleri etrafındaki düșük Reynolds sayll akıșın kontrolü ve aerodinamik performansın incelenmesi,' Ph.D. Dissertation, Natural and Applied Sciences Institute, Erciyes University, 2009.

xii. J. F Manwell,J. G.McGowan and A. L. Rogers 'Wind energy explained: theory design and application', Wiltshire: John Wiley \& Sons Ltd,2009. F. Molland,A. S Bahaj,J. R.Chaplin and W. M. J.Batten 'Measurements and predictions of forces, pressures and cavitation on 2-D sections suitable for marine current turbines,' in Proceedings of the Institution of Mechanical Engineers, Part M: Journal of Engineering for the Maritime Environment. 2008.

xiii. Muratoglu, and M.I. Yuce'Performance Analysis of Hydrokinetic Turbine Blade Sections'2015.

xiv. T. Nitin, N.D. Mittal, S.Ahmed, Investigation of blade performance of horizontal axis wind turbine based on blade element momentum theory (BEMT) using NACA airfoils, International Journal of Engineering, Science and Technology, Vol. 2, No. 12, pp. 25-35, 2010.

xv. P. Crimi.'Experimental Study of the Effects of Sweep on Hydrofoil Loading and Cavitation' 2012.

xvi. S. H. Person, 'Composite rotor design for a hydrokinetic turbine,' Thesis Projects, Mechanical Engineering, University of Tennessee, Knoxville, 2009. 